\title{
D esafios da sociedade do conhecimento e gestão de pessoas em sistemas de informação
}

\author{
M aria Cláudia Pestana \\ Supervisora técnica do Serviço de Tratamento da Informação. \\ Faculdade de M edicina Veterinária e Zootecnia - USP \\ E-mail: pestana@usp.br
}

\section{Pedra Margarete de Siqueira G uidil Pires}

Supervisora técnica do Serviço de Atendimento ao Usuário. Faculdade de M edicina Veterinária e Zootecnia - USP

E-mail: pmags@usp.br

\section{Vânia M artins Bueno de O liveira Funaro}

Supervisora técnica do Serviço de Informação Documentária e Circulação. Faculdade de O dontologia - U SP

E-mail: vaniamar@usp.br

\section{Assako Sumiyasu U tuyama}

Bibliotecária. Escola de Enfermagem - USP

\section{Floripes de M oura Pacheco}

Bibliotecária. Instituto de Estudos Brasileiros - USP

Teresa Beatriz N unes G uimarães

Bibliotecária. M useu de Zoologia - USP

\section{Resumo \\ Após passarmos de uma economia essencialmente agrícola para a industrial, pode-se dizer que a informação hoje é um novo tipo de "economia" que tanto pode dominar os setores quanto desenvolvê-los, e um dos grandes desafios da sociedade do conhecimento é a formação de líderes para a gestão de pessoas. Os líderes devem ter a capacidade de criar, motivar, manter o trabalho em equipe, visando sempre aos objetivos almejados de uma organização.}

\section{Palavras-chave}

Administração de pessoal; Liderança; Gestão de pessoas; Administração de empresas; Motivação (psicologia).

Challenges of the society of the knowledge and the management of people in information systems

\section{Abstract \\ After we have gone through from an essentially agricultural to an industrial economy, it can be said that information today is a new kind of "economy" that can both dominate the sectors and develop them. One of the greatest challenges of the society of knowledge is to train leaders for managing personnel. The leaders must be able to create, motivate and keep the team work, always seeking the objectives of the organization}

\section{Keywords}

Managing people; Lidership; Business administration; Motivation (psychology).

\section{IN TRO D U ÇÃO}

D urante o processo econômico mundial, tivemos a evolução de uma economia essencialmente agrícola para a industrial. Atualmente, podemos dizer que, além da industrial, temos a "economia do conhecimento", pois a sociedade que tem acesso à informação pode tanto dominar setores como desenvolvê-los (Andriani \& Zomer, 2002). A partir disso, então, define-se que a sociedade do conhecimento tem como ponto central o "saber", pois "o conhecimento, enquanto força de produção, representa o ponto nevrálgico entre os países centrais e periféricos" ( C arvalho \& Kaniski, 2000). Portanto, o conhecimento tem como conseqüência a geração de riqueza para quem o possui.

D esde o início da sociedade, a biblioteca tem sido uma das responsáveis pela organização da informação, tornando-seuma "acumuladora deconhecimento", não necessariamente uma disseminadora. Com as novas tecnologias de apoio e com a mudança de postura do bibliotecário, podemos verificar que houve avanço nessa divulgação. No caso da tecnologia, tivemos como principal acontecimento a Internet, que elimina barreiras geográficas e temporal, tornando o mundo globalizado.

Apesar dessas facilidades, podemos dizer que na Internet ainda impera o caos informacional, pois, conforme Carvalho \& Kaniski (2000, p. 37), "éilusório defender que a aplicação das tecnologias da informação elimina a necessidade da organização do conhecimento". Para que exista essa organização, deve-se estabelecer parcerias entre instituições para quehaja acesso à informação útil de maneira rápida, eficaz e eficiente.

Q uanto à postura do bibliotecário, este já não é mais visto como simples guardador de livros, mas sim como gerente e administrador, tanto de pessoas como do conhecimento. Portanto, deve ser uma pessoa ágil e dinâmica, com uma visão moderna de gestão e organização.

“Enfim, as bibliotecas saíram, ou devem sair, da postura de armazenadoras de informação para assumir uma postura centrada no processo de comunicação, o que significa abandonar a filosofia de posse e investir na filosofia de acesso. Esse investimento envolve o 


\section{Maria C láudia Pestana / Pedra M argarete de Siqueira G uidil Pires / V ânia M artins B ueno de 0 liveira Funaro / A ssako Sumiyasu U tuyama / Floripes de Moura Pacheco / Teresa Beatriz N unes G uimarães}

compartilhamento de recursos informacionais, o trabalho em rede, minimizando pontos deficitários e eliminando barreiras. N esse sentido, as tecnologias da informação representam a possibilidade mais concreta para expandir a cooperação interinstitucional e com isso ampliar e diversificar os pontos de acesso à informação" (Carvalho \& Kaniski, 2000, p. 37).

Para isso, énecessário que existam pessoas capacitadas para atender às necessidades da instituição e dos clientes, o que deve considerar a questão da gestão de pessoas, incluindo aí a liderança, o trabalho em equipe com pessoas motivadas ea capacitação de recursos humanos.

\section{GESTÃo dE PESSOAS}

A busca constante por processo de gestão de pessoas faz parte da organização quevisa cada vez mais à satisfação deseus funcionários para que, motivados, executem suas tarefas com eficiência e eficácia.

U m novo tipo de gestão de pessoas está sendo utilizado por algumas empresas dos Estados U nidos, efoi batizado de business-to-employee - da empresa para o empregado - ou B2E.

Este tipo de gestão permite que as empresas satisfaçam às necessidades dos funcionários e ao mesmo tempo reorganizem processos que demandam tempo emão-deobra.

Embora ainda não exista uma conclusão verdadeira quanto ao emprego destetipo degestão, alguns benefícios puderam ser verificados nas empresas em que foi implantado, tais como:

- maior facilidade na interação, mais autonomia nos serviços aos funcionários, personalização em massa e integração da vida pessoal com a profissional;

- a melhoria dos processos empresariais reduz os custos das transações entre compradores e vendedores nos mercados externos;

- a melhoria do gerenciamento de pessoas proporciona mais liberdade aos funcionários com o auto-serviço personalizado, pois o treinamento é autogerenciado, permitindo ao funcionário que escolha o curso que necessita fazer e matricula-seon-line. Em contrapartida, os gestores têm acesso a todas as informações referentes a relatórios da empresa e verificam os cursos que seus funcionários estão fazendo ou estão matriculados. Este auto-serviço on-line gera menos estresse e burocracia do que fazer tudo pessoalmente, sem contar com a economia de tempo, que poderá ser aplicado para desenvolver novas atividades;

- a melhoria dos serviços prestados à comunidade do local de trabalho: ao utilizar o portal da empresa para realizar atividades pessoais e profissionais no trabalho, o funcionário não necessita fazer isso em sua casa, 0 que o deixa mais satisfeito e demonstra maior comprometimento em suas tarefas, e com essa satisfação tende a trabalhar muito melhor ( $\mathrm{H}$ ansen $\&$ D eimler, 2001).

Estetipo degestão de pessoas necessita de infra-estrutura muito grande e alto investimento, o que deve ser analisado pela empresa que quer incorporá-lo.

$\mathrm{H}$ ansen \& Deimler (2001, p. 64 ) concluem que:

“D epois de levar em conta questões de custo e especialização, os gerentes devem pensar 0 que 0 gerenciamento B2E oferece. A verdadeira promessa não são pequenas reduções de custos e pequenos aumentos de produtividade, e sim uma forma digital de operar e trabalhar que enfatize tanto a produtividade como as pessoas."

Para Chiavenato (1994), existe uma grande diferença entre gerenciar pessoas e gerenciar com pessoas. N o primeiro caso, as pessoas são o objeto da gerência, são guiadas e controladas para alcançar determinados objetivos. N o segundo caso, as mesmas são o sujeito ativo da gerência, são elas que guiam e controlam para atingir os objetivos da organização e os objetivos pessoais.

Gerenciar pessoas ou a gestão de pessoas éa preocupação de muitas organizações para que seus objetivos sejam atingidos, de preferência com a participação deum grupo eficaz e motivado liderado por um gestor que possa ter os seguintes desafios estratégicos nesta atividade, segundo Fisher \& Albuquerque (2001, p. 16):

- "atrair, capacitar e reter talentos;

- gerir competências;

- gerir conhecimento;

- formar novo perfil do profissional demandado pelo setor;

- gerir novas relações trabalhistas; 
D esafios da sociedade do conhecimento e gestão de pessoas em sistemas de informação

- manter motivação/ clima organizacional;

- desenvolver uma cultura gerencial voltada para a excelência;

- $\mathrm{RH}$ reconhecido como contributivo para o negócio;

- $\mathrm{RH}$ reconhecido como estratégico;

- conciliar redução de custo e desempenho humano de qualidade;

- equilíbrio com qualidade de vida no trabalho;

- descentralizar gestão de RH ".

\section{COMPETÊNCIAS REQUERIDAS}

Para o processo de desenvolvimento de gestores, Rhinesmith* (1993, apud Vergara, 2000) propõe as seguintes competências:

- M entalidade: o profissional deve ter uma constante adaptação ao novo, verificando as dificuldades e tranformando-as em oportunidades. Busca constantemente estar aberto a si próprio e a novas propostas do grupo, mudando a direção e conduta quando necessário para melhor desempenho da instituição e do trabalho em equipe.

\section{- Características pessoais:}

Conhecimento amplo e profundo dos aspectos técnicos edo negócio para que possa contribuir de maneira efetiva no processo competitivo.

Conceituação: capacidade de lidar com o pensamento complexo eabstrato direcionando para a análise esíntese da situação apresentada na organização.

Flexibilidade: habilidade necessária de lidar com mudanças rápidas permitindo melhor liderança com os processos.

Sensibilidade: estar sensível às diferenças individuais apresentadas no grupo. Para tanto, é necessário estar ligado ao processo - não só emocionalmenteequilibrado, mas também predisposto a receber outros pontos devista, questionando, quando necessário, suposições, valores e conviç̧ões.
Julgamento: estar apto a lidar com incertezas cada vez mais presentes nas decisões gerenciais.

Reflexão: estar sempre predisposto a um aprendizado contínuo que lhe permitirá refletir sobre os problemas apresentados no grupo ou na organização.

- Competência: é "uma capacidade específica de executar a ação em um nível de habilidade que seja suficiente para alcançar o efeito desejado" (Rhinesmith, 1993, apud Vergara, 2000, p. 38).

Segundo Vergara (2000), mentalidadenão écompetência. A competência se estabelece a partir de uma mentalidade transformada em comportamento, assim como característica não é competência. U ma pessoa pode ser sensível para lidar com diferenças individuais, mas não usar essa sensibilidade no trabalho em equipe. Essa sensibilidade transforma-se em competência gerencial quando o gestor a usa para conhecer a si e o que está ao seu redor, bem como para criar, desenvolver e manter as equipes de trabalho direcionadas a atingir os mesmos objetivos.

Para Rhinesmith (1993, apud Vergara, 2000, p. 38), as competências a seguir completam as mencionadas anteriormente:

- gestão de competitividade: capacidade de colher informações em uma base global e aplicá-las;

- gestão da complexidade: capacidade de lidar com vários interesses concorrentes, contradições e conflitos;

- gestão de adaptabilidade: estar flexível e aberto para mudanças;

- gestão de equipes: capacidade de lidar com as diversas habilidades funcionais em níveis diferenciados de experiência e diversas origens culturais;

- gestão da incerteza: capacidade de lidar com mudanças contínuas. Para evitar que o gestor tenha uma sensação de impotência, énecessário quese prepare para a mudança, e não contra ela;

- gestão do aprendizado: capacidade do conhecimento/aprendizado próprio, bem como facilitar o conhecimento/ aprendizado dos outros.

\footnotetext{
* RHINESM ITH, S. G uia gerencial para globalização. Rio de Janeiro: Berkeley, 1993.

Ci. Inf., Brasília, v. 32, n. 2, p. 77-84, maio/ago. 2003
} 


\section{M aria C láudia Pestana / Pedra Margarete de Siqueira G uidil Pires / V ânia M artins Bueno de 0 liveira Funaro / A ssako Sumiyasu U tuyama / Floripes de Moura Pacheco / Teresa Beatriz N unes G uimarães}

Para Katz* (1974, apud Vergara, 2000, p. 39), existem três tipos de habilidades nas empresas: as técnicas, as humanas e as conceituais, que variam à medida que se encaminham entre os níveis supervisão, intermediária e alta direção. Q uando se passa do nível inferior para o superior, há aumento nas habilidades conceituais, em detrimento das habilidades técnicas.

Com a contínua mudança e complexidadeocorridas nas organizações ea forma como os gestores têm de atuar, ficam cada vez mais evidentes as diferenças entre os momentos eos espaços em queas diversas competências sefazem necessárias.

Vergara (2000, p. 97) elenca as seguintes capacidades requeridas para o gestor:

- compartilhar visão, missão, objetivos, metas, estruturas, tecnologias e estratégias;

- perscrutar, monitorar o ambiente externo;

- contribuir para a formação de valores e crenças dignificantes;

- ter habilidade na busca de clarificação de problemas;

- ser criativo;

- fazer da informação sua ferramenta de trabalho;

- ter iniciativa, comprometimento, atitude sinérgica, ousadia;

- visualizar o sucesso;

- construir formas deauto-aprendizado;

- conhecer seus pontos fortes e os fracos;

- ouvir e ser ouvido;

- reconhecer que todo o mundo tem alguma coisa com que podecontribuir;

- viabilizar a comunicação;

- pensar globalmente e agir localmente;

- reconhecer o trabalho das pessoas;

* KATZ, R. L. Skills of an effective administrator. $\mathrm{H}$ arvard Business Review, Sept./ Oct. 1974.
- ter energia radiante;

- ser ético.

N os casos dos sistemas de informação, a capacidade de "fazer da informação sua ferramenta de trabalho" é o fator principal da existência desses sistemas, nos quais as bibliotecas estão inseridas.

Todas as outras capacidades se encaixam com os sistemas de informação, por ser muito abrangente a área de atuação nos diversos segmentos do mercado e da sociedade.

0 gestor de pessoas nos sistemas de informação tendea lidar com as atitudes individuais e com as de grupo, fazendo com que todos desempenhem bem o seu papel para atingir o objetivo final, que é a satisfação das necessidades informacionais dos clientes.

\section{LIDERAN ÇA}

Gerente é a mola propulsora responsável pela sobrevivência esucesso, ou não, de uma organização.

A excelência empresarial está intimamente ligada à excelência gerencial. Para o sucesso empresarial, as principais determinantes são visão, dedicação e integridade do gerente, e as principais habilidades e ferramentas gerenciais se resumem basicamente em liderança.

0 indivíduo é único e ímpar e se destaca na equipe de trabalho por suas diferenças; e, para desenvolver um bom trabalho em equipe, é necessário haver uma liderança.

D eacordo com Vinci (2002), os chefes estão seocupando cada vez mais com o desenvolvimento das pessoas, atendendo o potencial de cada um eas necessidades da organização. Alguns deles apresentam potencial de desenvolvimento técnico, e outros, para gestão de pessoas.

Segundo Chiavenato (1994, p. 137), liderança é “uma influência interpessoal exercida em uma dada situação e dirigida através do processo de comunicação humana, para consecução de um ou mais objetivos" e pode ser dividida em:

- liderança como influência: uma pessoa pode influenciar outra em função do relacionamento existente entreelas; 


\section{D esafios da sociedade do conhecimento e gestão de pessoas em sistemas de informação}

- liderança que ocorreem determinada situação: ocorre em dada estrutura social decorrente da atribuição de autoridade para a tomada de decisão;

- liderança dirigida pelo processo de comunicação humana, capacidade de induzir o grupo a cumprir as obrigações atribuídas a cada um com zelo e correção;

- liderança visando à concepção de um ou de diversos objetivos específicos: o líder como meio para atribuir seus objetivos ou necessidades.

Portanto, a liderança não deve ser confundida com direção ou gerência, que deveser conduzida por um bom líder que nem sempre ocupa o papel de diretor ou gerente dentro de uma organização. 0 líder deve estar presente em todos os níveis hierárquicos e em todas as áreas de atuação.

\section{ESTILOS DE LIDERANÇA}

Segundo Belluzzo (2002), a liderança divide-se em autocrática, democrática eliberal, conforme demonstra a tabela 1.

Em relação ao exposto, podemos dizer queo líder deve:

- focar nos objetivos a serem alcançados;

- orientar para a ação;

- ter confiança em si próprio e no grupo;

- ter habilidade para lidar e conviver com pessoas, fazer as coisas com e por meio das pessoas;

- ser criativo e inovador;

- ser flexível, estar aberto a mudanças;

- tomar decisões (pensar eagir diante deuma situação);

- desenvolver altos padrões de desempenho eavaliação, buscando excelência, eficiência, eficácia, produtividade equalidade.

\section{TRABALHO EM EQUIPE}

Para poder falar em trabalho de equipe, precisamos entender o significado dessa palavra. Segundo o dicionário H ouaiss (2001), equipe é um "conjunto de pessoas que se dedicam à realização de um mesmo trabalho". Esse grupo de pessoas devesaber qual a missão e objetivos da organização na qual ele está inserido.

0 trabalho em equipe é mais do que uma ferramenta de trabalho. É um recurso primordial para a produtividade, e, para tal, é necessário que a equipe desenvolva atividades para uma determinada missão, projeto ou qualquer desafio dentro da organização.

Em relação aos objetivos emissão da organização, existem alguns requisitos básicos para que a equipe seja eficaz (Maximiano, 1986, p. 22):

- missão - definição vocacional;

- resultados a serem alcançados - definição operacional;

- divisão de trabalho/ papel dos membros - definição instrumental.

Ao sintonizar esses requisitos dentro de uma equipe, a eficiência ea eficácia estarão presentes, pois a vocação para desenvolver determinadas tarefas será completada com a operacionalização e a utilização correta dos instrumentos de trabalho. Porém, montar uma equipe de trabalho nem sempreéfácil. Elencamos a seguir os erros mais comuns no trabalho de equipe (VAM OS tentar [...], 2002, p. 112):

- metas superdimensionadas;

- composição equivocada; 
M aria C láudia Pestana / Pedra M argarete de Siqueira G uidil Pires / Vânia M artins Bueno de 0 liveira Funaro / A ssako Sumiyasu U tuyama / Floripes de Moura Pacheco / Teresa Beatriz N unes G uimarães

- liderança ditatorial;

- falta de motivação;

- reuniões improdutivas;

- subjetividade na avaliação;

- sensação de injustiça.

Para obter sucesso na formação de equipes, énecessário haver a ideologia como fator de coesão e atração entre os indivíduos, pois, assim, os grupos se motivam para atingir os mesmos ideais, embora se saiba que é difícil conciliar visões e estilos em torno de um ideal comum nos ambientes de trabalho.

A percepção é outra fonte importante para a formação de uma equipe. $N$ ão basta apenas a convivência física, é necessário queas pessoas estejam organizadas para atingir os mesmos objetivos. A equipe é definida como tal se cada um de seus membros se identifica como pertencente à mesma identidade social (M aximiano, 1986).

Vergara (2000) cita que a primeira vantagem de se trabalhar em equipe é a agilidade na captação da informação e em seu uso. O utra vantagem é que as equipes têm tendência maior a assumir riscos, porque a responsabilidade pelos resultados fica compartilhada. Por último, quando o poder é compartilhado, normalmente as pessoas sentem-se responsáveis pelo resultado e incorporam o processo, sentindo-se motivadas. 0 autor ainda menciona que há diferenças entre os membros da equipe em relação aos valores e crenças das pessoas, suas visões do mundo eas motivações que conduzem a seus comportamentos. Para completar, estes itens de diferença acrescentam funções psíquicas, tipos de inteligência, critérios para avaliações, caráter e comportamento.

Em relação aos pontos importantes no trabalho em equipe, Vergara (2000, p. 166) relaciona:

- "consciência do propósito;

- explicitação de balizamentos;

- comunicação aberta;

- feedback contínuo;

- compartilhamento de informações;
- negociação;

- humildade intelectual;

- comportamento ético".

N as bibliotecas, ou sistemas de informação, cada setor e cada pessoa têm sua tarefa para executar e funcionam como uma engrenagem ondenenhuma peça pode falhar.

0 trabalho em equipe terá bons resultados se todos tiverem a visão do sistema, e não apenas do setor onde é desenvolvido determinado tipo de tarefa.

\section{MOTIVAÇÃO}

Segundo M aitland (2002, p. 7), motivação "éa força ou o impulso que leva os indivíduos a agir de uma forma específica".

São várias as teorias levantadas acerca da motivação, mas apenas três mantiveram credibilidade por um certo tempo, quesão:

- "a pirâmide denecessidades de M aslow, queacreditava que todos os indivíduos apresentavam uma hierarquia denecessidades que precisavam ser satisfeitas" ( $M$ aitland, 2002, p. 8);

- a teoria de dois fatores de H erzberg, que sugeriu dois grupos igualmente importantes para motivar uma equipe: fatores de higiene (condições no ambiente de trabalho); fatores motivadores (dizem respeito aos sentimentos de auto-realização ereconhecimento) (M aitland, 2002);

- "teoria deV room: existem duas partes que compõem a motivação: desejos individuais e as expectativas de alcançá-los" (M aitland, 2002, p.10).

As teorias elencadas são válidas, embora tenham características próprias dando mais destaque a alguns aspectos do que a outros. Contudo, temos a responsabilidade de aplicar a que melhor seadapta àquilo que se deseja, bem como a responsabilidade de motivar pessoas próximas no ambiente de trabalho.

As maiores influências sobre a motivação são as pessoas e 0 relacionamento entre elas. Pode-se influenciar e aprimorar muitos dos principais instrumentos de motivação, a fim de aumentar a quantidadee a qualidade do trabalho. 


\section{D esafios da sociedade do conhecimento e gestão de pessoas em sistemas de informação}

Alguns autores afirmam que as organizações propiciam ambiente de sofrimento, de tédio, de desespero e desconforto existencial (D ejours*', 1992, apud Vergara, 2002).

Outros, como Tracy** (1994 apud Vergara, 2002), afirmam que a maioria das pessoas perde 0 interesse pelo trabalho e segue por caminhos que levam, às vezes, à mediocridade.

Para que tal situação não ocorra nas organizações, é necessário que o gestor de pessoas exerça o papel de motivador, fazendo com que as tarefas sejam desempenhadas com eficiência, eficácia e prazer.

H artman \& H orman (1990, apud Vergara, 2002, p. 66) mencionam os seguintes elementos como sendo significativos no trabalho:

- "promoção da aprendizagem e do desenvolvimento social nas atividades da sociedade;

- oportunidade de proporcionar às pessoas um papel social nas atividades da sociedade;

- promoção, na pessoa, da sensação de estar contribuindo, de pertencer, de ser apreciado, o que permite desenvolver sua auto-estima;

- oportunidade de produzir bens e serviços desejados pela sociedade;

• promoção e satisfação".

O s elementos anteriormente mencionados têm grau de importância bastante relevante, pois abrangem as oportunidades que as organizações podem oferecer às pessoas como forma de motivação, independentemente do fator salário, que muitas vezes éo atrativo para queo funcionário permaneça na organização.

Pesquisa realizada com 150 executivos mostra que $37 \%$ valorizam mais o plano de carreira com remuneração variável. Apenas $3 \%$ dos entrevistados colocaram como prioridade central o salário fixo. Aspectos como benefícios e boas condições de trabalho ficaram atrás da valorização do plano de carreira (Sammogini, 2002).
É importanteser um bom líder, e para isso énecessário saber exatamente aonde se quer chegar, como chegar e quando chegar. Juntamente com uma liderança bem exercida, o trabalho em equipe possui um papel importante na motivação.

D eve-se empregar diversas táticas de forma que todos trabalhem em conjunto, buscando o êxito. Essas equipes são motivadas pelas pessoas que têm em volta de si, e deve-se considerar a satisfação dentro do trabalho avaliando os funcionários e suas atribuições.

\section{CONSIDERAÇÕES FIN AIS}

Após feita breve revisão da literatura referente ao tema "D esafios da sociedade do conhecimento e gestão de pessoas em sistemas de informação", podemos fazer as seguintes considerações:

- gerenciar pessoas édiferentedegerenciar com pessoas;

- não necessariamentegerente éo líder;

- para uma forte equipe de trabalho, é necessário um bom líder;

- para um bom trabalho em equipe, é necessário ter uma visão do sistema com um todo;

- é necessário que existam condições ambientais e profissionais para a motivação de pessoal.

Os sistemas de informação estão inseridos no contexto organizacional no qual o gestor de pessoas deve estabelecer parâmetros para que o trabalho em equipe seja desenvolvido de acordo com os desafios que estão presentes no dia-a-dia de trabalho dos bibliotecários, profissionais tão fundamentais para este processo.

A rtigo recebido em 13-02-2003 eaceito para publicação em 23-06-2003

\footnotetext{
* DEJOURS, C. U ma nova visão do sofrimento humano nas organizações. In: CH ALAT, J.-F. (Org.). 0 indivíduo na organização. São Paulo: Atlas, 1992.

** TRACY, D. 10 passos para o empowerment. Rio de Janeiro: Campus, 1994.
}

Ci. Inf., Brasília, v. 32, n. 2, p. 77-84, maio/ago. 2003

\section{A tigo recebido em 13-02-2003 eaceito parapublicaçăo em 23-06-2003}




\section{Maria C láudia Pestana / Pedra M argarete de Siqueira G uidil Pires / V ânia M artins Bueno de 0 liveira Funaro /}

A ssako Sumiyasu U tuyama / Floripes de Moura Pacheco / Teresa Beatriz N unes G uimarães

\section{REFERÊ N CIAS}

ANDRIANI, Y. M. H.; ZOMER, S. S. Inteligência empresarial estratégica na sociedade do conhecimento. Disponível em: < http:// ww w.ijuris.org/ inteligencia/ ie2/downloads/ie2/ Intlg\%20\%20Soc\%20Conhec.doc>. Acesso em: 03 out. 2002.

BELLUZZO, R. C. B. Liderança \& formação e desenvolvimento de equipes. São Paulo : USP, SIBi, 2002. Apostila.

CARVALH O, I. C. L.; KANISKI, A. L. A sociedade do conhecimento e o acesso à informação: para que e para quem? Ciência da Informação, Brasília, v. 29, n. 3, p. 33-39, set./ dez. 2000.

CHIAVENATO, I. Gerenciando pessoas. 2 ed. São Paulo : Makron Books, 1994.

FISCHER, A. L.; ALBUQUERQUE, L. G. de. Relatório de pesquisa tendências demudançasna gestão depessoas das empresas brasileiras: $D E L P H I$ RH -2010. [São Paulo] : M BA, U SP, 2001. 18 p.
H AN SEN , T.; DEIM LER, M . S. Cutting cost while improvinh morale with B2E management. Sloam M anagement Review, p. 96-100, Autumm 2001. São Paulo, v. 6, n. 3, p. 122-130, mar./abr. 2002.

HOUAISS DA LÍNGUA PORTUGUESA. Rio de Janeiro : Objetiva, 2001. p. 2922.

M AITLAN D, I. Como motivar pessoas. São Paulo : N obel, 2002.

M AXIMIANO, A. C. A. Gerência de trabalho de equipe. São Paulo: Pioneira, 1986.

SAM M OGINI, A. Planejamento vira prioridade profissional. Folha de S. Paulo, São Paulo, 18 ago. 2002. Classificados Empregos. p. 2.

VERGARA, S. C. G estão de pessoas. 2. ed. São Paulo : Atlas, 2000.

VAM OS tentar outra vez: mais um método para dar fôlego novo ao velho trabalho em grupo. Veja, São Paulo, n. 1742, p. 112, mar. 2002.

VINCI, A. O chefe não manda mais. O Estado de São Paulo, São Paulo, 18 ago. 2002. Classificados Empregos. 